Illinois State University

ISU ReD: Research and eData

Theses and Dissertations

4-7-2020

\title{
The Relationship Between The Prevalence Of Cardiovascular Disease And Health Risk Appraisals In College-Age Students
}

Brandi Curtis

Illinois State University, brandilynncurtis@gmail.com

Follow this and additional works at: https://ir.library.illinoisstate.edu/etd

Part of the Medicine and Health Sciences Commons

\section{Recommended Citation}

Curtis, Brandi, "The Relationship Between The Prevalence Of Cardiovascular Disease And Health Risk Appraisals In College-Age Students" (2020). Theses and Dissertations. 1248.

https://ir.library.illinoisstate.edu/etd/1248

This Thesis is brought to you for free and open access by ISU ReD: Research and eData. It has been accepted for inclusion in Theses and Dissertations by an authorized administrator of ISU ReD: Research and eData. For more information, please contact ISUReD@ilstu.edu. 
THE RELATIONSHIP BETWEEN THE PREVALENCE OF CARDIOVASCULAR DISEASE AND HEALTH RISK APPRAISALS IN COLLEGE-AGE STUDENTS

\section{BRANDI CURTIS}

\section{Pages}

The purpose of this study is to investigate the prevalence of cardiovascular disease risk factors in college-age students as compared to their health risk appraisal score for cardiovascular disease. Two-hundred fifty-seven females and two-hundred eight males from a moderately-sized, midwestern university participated in the study with the subjects having a mean age of $21.1 \pm 2.1$ yr. and $21.6 \pm 2.3 \mathrm{yr}$., a BMI of $23.9 \pm 4.6$ and $25.7 \pm 4.0$, and a body fat of $27.9 \pm 8.9 \%$ and $17.9 \pm$ $8.5 \%$, respectively. All testing was completed during a single session. Height and weight were obtained to calculate body mass index (BMI). Physical fitness assessments were obtained but not analyzed in this study. Blood lipid levels were obtained on subjects, requiring them to report to the laboratory having fasted and restricting fluid intake 12 hours prior to testing. Descriptive statistics were used to summarize the results with averages for females and males of the most prevalent risk factors: HDL cholesterol, LDL cholesterol, total cholesterol, triglycerides, blood glucose, diastolic blood pressure, and systolic blood pressure. The averages for HDL cholesterol were $64.3 \pm 17.6$ and $51.2 \pm 13.6 \mathrm{mg} / \mathrm{dL}$ for females and males, respectively. The averages for LDL cholesterol were $78.5 \pm 26.7$ and $77.5 \pm 31.0 \mathrm{mg} / \mathrm{dL}$ for females and males, respectively. The average for total cholesterol were $163.6 \pm 33.8$ and $148.8 \pm 31.3 \mathrm{mg} / \mathrm{dL}$ for females and males, respectively. The average for triglycerides were $108.9 \pm 54.8$ and $111.6 \pm 115.8 \mathrm{mg} / \mathrm{dL}$ for females and males, respectively. The average for blood glucose was $89.5 \pm 15.9$ and $90.6 \pm$ 
$12.3 \mathrm{mg} / \mathrm{dL}$ for females and males, respectively. The average for diastolic blood pressure was $64.7 \pm 14.8$ and $70.2 \pm 12.2 \mathrm{~mm} \mathrm{Hg}$ for females and males, respectively. The average for systolic blood pressure was $103.9 \pm 20.3$ and $114.7 \pm 17.7 \mathrm{~mm} \mathrm{Hg}$ for females and males, respectively. While most of the subjects were in the "desirable" cut point range, there is a prevalence of cardiovascular disease and metabolic syndrome risk. When compared to the health risk appraisal data scores, the majority of the low risk scores had desirable levels for total cholesterol, LDL cholesterol, triglycerides, and body mass index. In terms of HDL cholesterol, the low risk group category was almost evenly split between optimal levels and suboptimal levels. These results demonstrate that health risk appraisals (HRA) in college students provide a very good prediction of their physical assessment of cardiovascular disease. The HRA scores aligned closely with their biomedical data. While only $2.1 \%$ of the students would be classified with metabolic syndrome, $41 \%$ of college age students have one or more of the risk factors for metabolic syndrome. This study suggests that the implementation of a similar health risk appraisal, could help health care providers identify and screen for cardiovascular disease risk factors earlier. It was concluded that education and awareness of cardiovascular disease risk factors is needed in college age students.

KEYWORDS: Cardiovascular Disease, College-Age Students, Health Risk Appraisal, Metabolic Syndrome, Cardiovascular Disease Risk Factors 
THE RELATIONSHIP BETWEEN THE PREVALENCE OF CARDIOVASCULAR DISEASE AND HEALTH RISK APPRAISALS IN COLLEGE-AGE STUDENTS

BRANDI CURTIS

\author{
A Thesis Submitted in Partial \\ Fulfillment of the Requirements \\ for the Degree of \\ MASTER OF SCIENCE
}

School of Kinesiology and Recreation

ILLINOIS STATE UNIVERSITY 
Copyright 2020 Brandi Curtis 
THE RELATIONSHIP BETWEEN THE PREVALENCE OF CARDIOVASCULAR DISEASE AND HEALTH RISK APPRAISALS IN COLLEGE-AGE STUDENTS

BRANDI CURTIS

COMMITTEE MEMBERS:

Dale D. Brown, Chair

Kelly R. Laurson

Karen K. Dennis

Megan M. Weemer 


\section{ACKNOWLEDGMENTS}

I would like to thank my committee members Dr. Dale Brown, Dr. Kelly Laurson, Dr. Karen Dennis, and Dr. Megan Weemer for serving on my committee and helping me complete my research. I would especially like to thank my thesis chair, Dr. Dale Brown for helping me to organize my data, helpful comments, tools, and encouragement through the process. In addition, I would like to thank Dr. Karen Dennis for allowing me to use her class's data for my project. Lastly, I would like to thank my fellow peers in my cohort for continuous support and encouragement.

B.C. 


\section{CONTENTS}

Page

ACKNOWLEDGEMENTS

CONTENTS

TABLES $\quad$ iii

CHAPTER I: THE RELATIONSHIP BETWEEN THE PREVALENCE OF

CARDIOVASCULAR DISEASE AND HEALTH RISK APPRAISALS IN COLLEGEAGE STUDENTS 1

$\begin{array}{ll}\text { Introduction } & 1\end{array}$

Methods 3

Subjects \& Procedures 3

Assessments and Screenings. Body Mass Index and Waist Circumference 3

Body Composition Assessment 4

Physical Fitness Assessment 4

Blood Cholesterol/Glucose Screening 5

Health Risk Appraisal

Data/Statistical Analysis $\quad 6$

$\begin{array}{ll}\text { Results } & 7\end{array}$

$\begin{array}{ll}\text { Discussion } & 9\end{array}$

$\begin{array}{ll}\text { Conclusion } & 13\end{array}$

$\begin{array}{ll}\text { References } & 26\end{array}$

CHAPTER II: EXTENDED REVIEW OF LITERATURE 29

$\begin{array}{ll}\text { References } & 49\end{array}$ 


\section{TABLES}

Table

Page

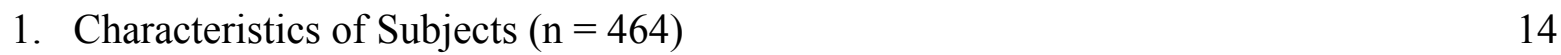

2. Average Blood Lipid/Blood Glucose Values by Sex $(n=464)$

3. Distribution of Total Cholesterol by Sex $(n=464) \quad 16$

4. Distribution of High-Density Lipoprotein Cholesterol by Sex $(n=464)$

5. Distribution of Low-Density Lipoprotein Cholesterol by Sex $(n=464) \quad 18$

6. Distribution of Triglycerides by Sex $(n=464) \quad 19$

7. Distribution of Blood Glucose by Sex $(n=464) \quad 20$

8. Distribution of Subjects with Metabolic Syndrome Based on Number of Risk

Factors $(n=464)$

9. Distribution of Subjects by Sex with Metabolic Syndrome Based on Number of Risk

Factors $(\mathrm{n}=464)$

10. Metabolic Syndrome Risk Factors in College Students $(n=464)$

11. Relationship Between Cardiovascular HRA and Blood Lipids/Glucose $(n=464)$

12. Longitudinal Analysis of Metabolic Syndrome Risk Factors in College Students $(\mathrm{n}=464)$ 


\section{CHAPTER I: THE RELATIONSHIP BETWEEN THE PREVALENCE OF \\ CARDIOVASCULAR DISEASE AND HEALTH RISK APPRAISALS IN \\ COLLEGE-AGE STUDENTS}

\section{Introduction}

An estimated 81 million adult Americans have one or more types of cardiovascular disease. Cardiovascular disease remains as the number one cause of death for men and women in the United States. Worldwide, eighteen million deaths per year are attributed to cardiovascular disease (7). Heart disease costs the United States about \$219 billion each year from 2014 to 2015. This includes the cost of health care services, medicines, and lost productivity due to death (6).

The purpose of the cardiovascular system is to deliver oxygen and other nutrients to the heart, remove carbon dioxide and other metabolic waste, transport hormones, thermoregulation, maintenance of acid-base balance and overall body fluid balance, and support immune function (8). Oftentimes but not always, the disease state starts with elevated blood pressure or hypertension. Hypertension is the primary risk factor for heart disease (8). If it goes untreated, malfunctions in the cardiovascular system's function occur. Moreover, it can lead to further diseases such as atherosclerosis, heart failure, end-stage renal disease, and peripheral vascular disease. "The prevalence of hypertension increases with advancing age to the extent that half of the people aged sixty to sixty-nine years and approximately three fourths of people seventy years and older are affected" (12). Its prevalence makes the topic a highly researched area.

Various research studies have been completed, examining associated disease states, therapy, treatment options, effectiveness of medications, how to maintain balance for older 
individuals to keep quality of life, modifiable and non-modifiable risk factors. While research has helped us to learn more about the disease state and its interventions, the disease state is not subsiding, and its prevalence continues to remain high. This is an important piece of information indicating the need for continued research to be conducted. The biggest strength of previous research is that we can correlate factors that may cause cardiovascular disease over time. Researchers have also studied the correlations with other disease states. From those studies, treatment options and medications have been implemented to improve an individual's quality of life.

A limitation for published research is the evidence for the effectiveness of prevention over a long period of time. Research has revealed cardiovascular disease causation and interventions individuals can take to prevent disease, but we do not see much research on the impact of these prevention methods in the long run. This is partially due to the complication of the type of study. Individuals would need to be monitored for years of their life while adhering to these prevention methods to evaluate the effectiveness. While this would be an informative research study, it would not be the most feasible to conduct.

Because previous research has correlated factors that may cause cardiovascular disease over time, one can conclude that educating and implementing lifestyle interventions at a younger age is the most ideal way to prevent cardiovascular disease. With college-age students, some of their behaviors may contribute to their risk. With their busy lives, onset of independence, and attitudes, some may not have the time, desire, or awareness of behaviors to implement a lifestyle that could reduce their risk later on in life.

Most young adults are not screened and/or are unaware of their risk (4). More than onehalf of young adults aged 18-24 years old have at least one coronary heart disease risk factor and 
nearly one-quarter have advanced atherosclerotic lesions. The results of this study yield similar results. There is a need for further research among the young adult population about their behaviors and its relation to possible risk factors that could lead to cardiovascular disease in adulthood. The purpose of this study is to investigate the prevalence of cardiovascular disease risk factors in college-age students and compare to their health risk appraisal score for cardiovascular disease.

\section{Methods}

\section{Subjects \& Procedures}

The subjects in this study included 462 students from a moderately-sized, midwestern university. The sample included two-hundred fifty-seven females and two-hundred eight males with ages ranging from nineteen to forty-two. The students that took part in this study were enrolled in a fitness and health class that is offered by the university to all students with the data being collected over the past 10 years. Prior to commencement of any assessments and screenings, subjects completed and signed an institutionally approved informed consent, medical history, PAR-Q, and research release form. The Health Insurance Portability and Accountability Act (HIPAA) regulations were strictly followed. Once students turned in the signed/completed forms they were able to participate in the assessments and screenings.

\section{Assessments and Screenings. Body Mass Index and Waist Circumference}

The measurement of body mass index (BMI) was completed using height in meters and mass in kilograms. BMI was then calculated by dividing mass by height squared $\left(\mathrm{kg} / \mathrm{m}^{2}\right)$. Waist circumference was found by first having the subject stand with arms at their sides, feet together, and abdomen relaxed. Following, a measuring tape was used for a horizontal plane measure at 
the narrowest part of the torso, above the umbilicus and below the xiphoid process. The tape was drawn flush with the body but did not compress the skin. The measurement was made at the end of a normal expiration. Cut points were established for body mass index and waist circumference using The National Institute of Health guidelines.

\section{Body Composition Assessment}

Body weight and body composition were assessed using bioelectrical impedance through the Tanita ${ }^{\circledR}$ body composition analyzer (TBF-300A). Clothing weight was estimated for the subjects while each participant's age, gender, and height were manually entered into the Tanita ${ }^{\circledR}$ analyzer. The Tanita ${ }^{\circledR}$ body composition analyzer has two stainless-steel foot electrodes mounted on a platform scale. Each subject was asked to remove their shoes and socks before the start of the test (per manufacturer's instructions). After subject demographic data (age, gender, and height) was entered into the Tanita ${ }^{\circledR}$ body composition analyzer, subjects were instructed to step onto the analyzer, placing the ball and heel of each foot on top of the aligning foot-pads of the analyzer. Their weight, as well as body fat percentage, were recorded from the Tanita ${ }^{\circledR}$ body composition analysis and then entered into the computer for analysis. Cut points were established for body fat percent using The National Institute of Health guidelines.

\section{Physical Fitness Assessments}

Physical fitness assessments were completed as a routine part of the subject's academic class. However, the fitness assessments were not analyzed in this study. Fitness assessments were supervised by a trained staff member. The assessments included: Queens College Step Test, hand-grip strength (right and left), push-ups, sit-ups, and sit and reach. The students were instructed on the protocol for each fitness test and received verbal encouragement from the laboratory personnel to attain a peak score. The subjects and staff documented all results. 


\section{Blood Cholesterol/Glucose Screenings}

All screenings were performed by certified personnel from a local medical center/hospital that routinely performs blood lipid/glucose analysis. Prior to the finger stick each subject had blood pressure taken and values were recorded as systolic blood pressure (SBP) over diastolic blood pressure (DBP). Blood samples were obtained via capillary finger stick blood sample with the subjects having fasted and restricted fluid intake, excluding water, twelve hours

prior to the test. The subject's blood samples were collected through the use of hospital approved equipment and analyzed by a Cholestech Analyzer (Edwards Medical). Results included total cholesterol (CHOL), high density lipoprotein (HDL), low density lipoprotein (LDL), triglycerides (TRI), and glucose (GLU) levels. Data from each of these assessments were recorded and entered into the Trifit Software database so that normative comparisons could be made. Cut points were established for blood lipid levels using The National Institute of Health guidelines.

\section{Health Risk Appraisal}

The Polar Health First/Trifit Software contains a health risk appraisal component that provides a systematic approach to collecting information related to one's risk for heart disease, cancer, diabetes, stress, and depression while also examining one's nutritional and safety/prevention behaviors. Students answered a series of questions that provided the basis for determination of their risk for developing diseases related to that specific health risk. It gave the participants a numbered score and a rank. What the criteria was for these categories is unknown. How these variables were calculated is unknown. The score range went from $0-16$. If the score was 0-2, it was a "low-risk" rank. If the score was 3-4, it was a "low-moderate" risk rank. If the 
score was 5-7, it was a "moderate-high" risk rank. If the score was 8-15, it was a "high" risk rank. If the score was 16 , it was a "very-high" risk rank.

Specific to this study, the cardiovascular disease HRA data was used and analyzed. Nine questions were asked in this HRA. The questions were as follows: "Have you been diagnosed with cardiovascular disease?", "Has a parent, brother, or sister been diagnosed with cardiovascular disease?", "Has a doctor told you that you have diabetes?", "How often do you engage in aerobic exercise?", “Are you taking anti-hypertensive medications?”, "What does your smoking habit look like?", "What is your blood pressure?", "What is your total cholesterol?”, "What is your high-density lipoprotein cholesterol?" These questions include both lifestyle factor questions and genetic predisposition questions. Comparisons of these scores and ranks to their blood lipid, blood glucose, and blood pressure values were made.

\section{Data/Statistical Analysis}

Data was entered into the Trifit software. Each variable was then categorized as to whether the scores exceed the healthy cut points for each of the variables. The cut points were established for metabolic syndrome using the National Cholesterol Education Program ATP III Guidelines, which include: triglycerides greater than $150 \mathrm{mg} / \mathrm{dL}$, blood pressure greater than 130/85 mmHg, impaired fasting glucose greater than $100 \mathrm{mg} / \mathrm{dL}$, HDL cholesterol less than forty $\mathrm{mg} / \mathrm{dL}$ for males and less than fifty $\mathrm{mg} / \mathrm{dL}$ for females, and a waist circumference greater than 40 in for males and 35 in for females. Students were identified as being at risk of metabolic syndrome if they had one or more risk factors.

Blood lipid levels were exported from the Trifit software to Microsoft Excel for analysis. Descriptive statistics were used to summarize the results of the study. Descriptive statistics was also utilized to determine the percentage of students that fell into each risk group for BMI, body 
fat percentage, and for blood lipid/blood glucose profiles. Cross tabulation was used to summarize the data and assist in the determination of percentages/prevalence of risk factors.

\section{Results}

The sample for this study consisted of 465 subjects, with 257 being female and 207 being males. The subjects had a mean age of $21.3 \pm 2.2$ years, a BMI of $24.7 \pm 4.5 \mathrm{~kg} / \mathrm{m}^{2}$, and a body fat percentage of $23.4 \% \pm 10.1 \%$, overall. The average age for females was 21.1 years and 21.6 years for males. The average BMI for females was $23.9 \mathrm{~kg} / \mathrm{m}^{2}$ and $25.7 \mathrm{~kg} / \mathrm{m}^{2}$ for males. The average body fat percentage for females was $27.9 \%$ and $17.9 \%$ for males. The demographic data is displayed in Table 1 .

The averages of blood lipid/blood glucose values by sex are displayed in Table 2. Of the females, the average total cholesterol was $163.7 \pm 33.8 \mathrm{mg} / \mathrm{dL}$, the average HDL was $64.3 \pm 17.7$ $\mathrm{mg} / \mathrm{dL}$, the average $\mathrm{LDL}$ was $78.5 \pm 26.7 \mathrm{mg} / \mathrm{dL}$, the average triglycerides were $108.9 \pm 54.6$ $\mathrm{mg} / \mathrm{dL}$, and the average blood glucose was $89.5 \pm 15.9 \mathrm{mg} / \mathrm{dL}$. Of the males, the average total cholesterol was $148.7 \pm 31.4 \mathrm{mg} / \mathrm{dL}$, the average HDL was $51.2 \pm 13.7 \mathrm{mg} / \mathrm{dL}$, the average LDL was $77.4 \pm 31.1 \mathrm{mg} / \mathrm{dL}$, the average triglycerides were $111.7 \pm 116.3$, and the average blood glucose was $90.6 \pm 12.3 \mathrm{mg} / \mathrm{dL}$. All of these values meet the "desirable" or "optimal" cut points. In addition, the majority of the subjects met the "desirable" or "optimal" cut point ranges for each blood lipid/glucose variable. This data is displayed in tables 3-7.

While most of the subjects were in the "desirable" cut point range, it is important to point out the prevalence of cardiovascular disease risk within this group in terms of blood lipids, blood glucose, and blood pressure values. In terms of blood lipid values, as shown in tables $3-7,17.4 \%$ of females and $8.3 \%$ of males had elevated cholesterol levels (Table 3), $29 \%$ of females and $67 \%$ 
of males had suboptimal levels for HDL cholesterol (Table 4), 27\% of females and $11 \%$ of males had elevated levels for LDL cholesterol (Table 5), and $26 \%$ of females and $34 \%$ of males had elevated triglyceride levels (Table 6). In terms of blood glucose levels, $18 \%$ of females and $24 \%$ of males had elevated levels and were considered either "prediabetic" or "diabetic" (Table 7). In terms of blood pressure, $2.3 \%$ of females and $4.8 \%$ of males had elevated systolic blood pressure, and $1.2 \%$ of females and $6.3 \%$ of males had elevated diastolic blood pressure (Table $11)$.

In addition, it is important to point out the prevalence of metabolic syndrome within this groups in terms of its cut points. The distribution of subjects with metabolic syndrome based on number of risk factors are displayed in Tables 9 and 10. The average number of metabolic syndrome risk factors across both sexes was 0.6 (Table 11); however, $41 \%$ of the subjects had one or more risk factors for metabolic syndrome and $2.1 \%$ of the subjects met the criteria for having metabolic syndrome (Table 9). When broken down by sex, Table 10 shows that $40 \%$ of females and $43 \%$ of males have one or risk factors for metabolic syndrome. In addition, the prevalence of specific metabolic syndrome risk factors is displayed in Table 10.

The health risk appraisal data in relation to the average blood lipid/blood glucose levels are displayed in Table 11. Overall, 378 were in the low risk rank, 46 were in the low moderate risk rank, 1 was in the moderate risk rank, 25 were in the moderate-high risk rank, and 11 were in the high-risk rank. For the low-risk group, the average HDL was $60.6 \mathrm{mg} / \mathrm{dL}$, the average LDL was $74.5 \mathrm{mg} / \mathrm{dL}$, the average cholesterol was $155.3 \mathrm{mg} / \mathrm{dL}$, the average triglycerides were $108.0 \mathrm{mg} / \mathrm{dL}$, the average glucose was $89.2 \mathrm{mg} / \mathrm{dL}$, and the average number of metabolic syndrome risk factors was 0.4 . For the low-moderate risk group, the average HDL was 51.7 $\mathrm{mg} / \mathrm{dL}$, the average LDL was $86.3 \mathrm{mg} / \mathrm{dL}$, the average total cholesterol was $160.4 \mathrm{mg} / \mathrm{dL}$, the 
average triglycerides were $103.2 \mathrm{mg} / \mathrm{dL}$, the average glucose was $90.0 \mathrm{mg} / \mathrm{dL}$, and the average number of metabolic syndrome risk factors was 0.9 .

For the moderate-risk group, the individual had an HDL of $61.0 \mathrm{mg} / \mathrm{dL}$, an LDL of 141.0 $\mathrm{mg} / \mathrm{dL}$, a total cholesterol of $226.0 \mathrm{mg} / \mathrm{dL}$, a triglyceride value of $118.0 \mathrm{mg} / \mathrm{dL}$, a glucose value of $101.0 \mathrm{mg} / \mathrm{dL}$, and 2 risk factors for metabolic syndrome. Of the moderate-high risk group, the average HDL was $43.1 \mathrm{mg} / \mathrm{dL}$, the average LDL was $99.5 \mathrm{mg} / \mathrm{dL}$, the average total cholesterol was $159.2 \mathrm{mg} / \mathrm{dL}$, the average triglycerides were $136.3 \mathrm{mg} / \mathrm{dL}$, the average glucose was 91.8 $\mathrm{mg} / \mathrm{dL}$, and the average number of metabolic syndrome risk factors was 1.5 . For the high-risk group, the average HDL was $47.3 \mathrm{mg} / \mathrm{dL}$, the average LDL was $108.8 \mathrm{mg} / \mathrm{dL}$, the average total cholesterol was $188.4 \mathrm{mg} / \mathrm{dL}$, the average triglycerides were $161.7 \mathrm{mg} / \mathrm{dL}$, the average glucose was $113.4 \mathrm{mg} / \mathrm{dL}$, and the average number of metabolic syndrome risk factors was 2.2. Overall, there was in increase in blood lipid/blood glucose values as the HRA risk rank increased.

\section{Discussion}

The purpose of this study was to investigate the prevalence of cardiovascular disease factor risk in college-age students and compare to their health risk appraisal score for cardiovascular disease. The results from this study show that majority of the subjects identified to have low risk HRA scores have desirable levels for total cholesterol, LDL cholesterol, triglycerides, and body mass index. In terms of HDL cholesterol, the low risk group category was almost evenly split between optimal levels and suboptimal levels. In terms of sex, there were more females in the low-risk category than males. Moreover, there were more males in the lowmoderate risk, moderate-high risk, and high-risk categories. In terms of age, majority of the population was 19-23 with 21 being the highest. Out of the 157 21-year old's, 133 were low-risk. 
This study demonstrated the accuracy of the health risk appraisal score aligns with the data. Specifically, these results demonstrate that health risk appraisals (HRA) in college students provide a very good prediction of their physical assessment of cardiovascular disease. Moreover, the student's answers to the related HRA questions aligned with their risk in terms of their found blood laboratory values. These data show there is a relationship between BMI, total cholesterol, diastolic blood pressure, systolic blood pressure, HDL cholesterol, LDL cholesterol, and triglycerides. The prevalence of cardiovascular disease and metabolic syndrome with this group is low with only $2.1 \%$ of the students being classified with metabolic syndrome, $41 \%$ of college age students have one or more of the risk factors for metabolic syndrome.

This data adds to and extends the previous work that has been completed on this data (Table 12). Previous analysis of the data was conducted in 2014 and 2018. In the 2014 analysis, there were 141 subjects contained within the research data base, and that study examined the data which were collected to date at that point in time. In 2018, a cross sectional sampling of 70 subjects from that calendar year were analyzed. Those previous investigations showed that in 2014 subjects with one or more risk factors made up $51.4 \%$ of the sample population compared to $39.4 \%$ in 2014 . The most dominant risk factor in 2018 was elevated triglyceride values in $21.4 \%$ of the population, paralleled to $11.5 \%$ in 2014 . Elevated blood glucose levels were found in $18.6 \%$ of the sample population and low HDL values in $17.1 \%$ of subjects likened to $9.8 \%$ and $16.5 \%$ respectively. Those with an elevated blood pressure comprised of $8.6 \%$ matched to $5.0 \%$ while and increase in systolic and diastolic blood pressure were reported in 5.7\% apiece compared to $2.5 \%$ and $4.0 \%$. The percentage of those that are at risk for metabolic syndrome have increased since 2014. Four of the five risk factors have increased as well. Young adults have shown to be at greater risk for metabolic syndrome now than they were in 2014 . 
Even though there were many similarities between the studies there were also obvious differences. Compared to the 2014 study, there was a growth in subjects that had one or more risk factors. The findings show $51.4 \%$ of the subjects totaled one or more risk factors. That is up $11.7 \%$ from 2014 which verified only $39.7 \%$ were at risk. This increase mostly come from a percentage increase in blood glucose and triglyceride levels. Those that had elevated blood glucose and triglyceride levels rose $8.8 \%$ and $9.9 \%$ respectively from the previous study. Higher levels of blood glucose and triglycerides levels can be a sign of overindulgence of non-healthy food choices (7). While there certainly were differences between the 2014 in the 2018 data it should be pointed out that the differences in the $\mathrm{n}$ size were such that the number of subjects might have contributed to the variability in the numbers presented. However, the data between the two 2020 and 2014 data we're relatively similar with the trends for the variables presented for the most part showing an increase in the prevalence of each of those risk factors.

Overall, early screening and education are where health care providers can start to reduce mortality and morbidity of heart disease. Previous studies have found that most young adults are not screened and/or are unaware of their risk (4). One of the studies researched found that health care professionals can play a big role in the education and evaluation of health behavior interventions with college students by designing, implementing, and evaluating health behavioral change interventions to manage risk (15). Melnyk, J.A., et al. and Nazar, M. et al. showed that an education intervention piece and an increase in health literacy can improve knowledge between cardiovascular disease and lifestyle behaviors. Specifically, the researchers provided personalized feedback and health education of diet, physical activity, cardiovascular disease risk factors, smoking habits, medications, signs and symptoms for a heart attack, and normative 
values for blood pressure and cholesterol to effectively increase awareness in this population (10, 12).

Tran, D. M. T. et al. showed by means of a questionnaire that the lack of awareness and screening are of concern and this targeted population could benefit from cardiovascular risk factor reduction programs (18). Similarly, Thiangalingam, U., et al. implemented a questionnaire that targeted questions regarding behaviors. The questionnaire results allowed the researchers to conclude that the epidemic of cardiovascular disease continues to grow, and it is due to the burden of cardiovascular risk factors (17). Implementing a questionnaire or a similar health risk appraisal as done in this study, could help health care providers identify and screen for cardiovascular disease risk factors earlier. After detection of a risk factor, education and increased health literacy could be implemented to further reduce risk. Sometimes, motivational tools may need to be implemented.

A limitation of this study would include this specific class of students. Because this group was specific to a personal fitness college class, it is safe to generalize that the majority of the students have an interest in their personal health. This prediction could have carried over into the data results. This is not a varied sample of college students and their behaviors; their fitness scores and blood profiles may not have been representative of all college students. Generally, several studies have shown that awareness and knowledge of the disease and its risk factors are low $(1,2,7,14)$. In addition, most research found pointed out how various behaviors of this population is putting them at risk $(1,2,8,12,13,14,15,16$.). Such behaviors include physical inactivity, smoking, alcohol consumption, dietary habits, and stress levels. 


\section{Conclusion}

In conclusion, the health risk appraisal (HRA) scores were reflective of the students' biomedical data. Specifically, this HRA provides a very good prediction of the students' physical assessment of cardiovascular disease. This study suggests that the implementation of a similar health risk appraisal, could help health care providers identify and screen for cardiovascular disease risk factors earlier. Evidence has shown that college age students need more education at a younger age, heart disease can be prevented at this age, and healthcare providers play an important role in educating young adults on what they can do to lower their risk. Screening and education for cardiovascular disease is very important. Oftentimes, asymptomatic individuals are unaware of their risk because they've never been screened or tested. As a result, individuals are unaware of their risk until they have the disease. By then, treatment is the only solution. There is a need for further research among the adolescent population about their behaviors and its relation to possible risk factors that could lead cardiovascular disease in adulthood. 
Table 1. Characteristics of Subjects $(n=464)$

\begin{tabular}{llllll}
\hline & $\begin{array}{l}\text { Age } \\
\text { (yrs) }\end{array}$ & Height (in) & $\begin{array}{l}\text { Weight } \\
\text { (lbs) }\end{array}$ & BMI & $\begin{array}{l}\text { Body } \\
\text { Composition } \\
\text { (\% fat) }\end{array}$ \\
\hline Females & 21.1 & 64.8 & 144.1 & 23.9 & 27.9 \\
& 2.1 & 4.9 & 30.8 & 4.6 & 8.9 \\
Males & 21.6 & 70.3 & 182.4 & 25.7 & 17.9 \\
& 2.3 & 3.1 & 31.7 & 4.0 & 8.5 \\
Totals & 21.3 & 67.2 & 161.2 & 24.7 & 23.4 \\
& 2.2 & 5.1 & 36.6 & 4.5 & 10.1 \\
\hline
\end{tabular}


Table 2. Average Blood Lipid/Blood Glucose Values by Sex $(n=464)$

\begin{tabular}{llllll}
\hline & $\begin{array}{l}\text { Blood } \\
\text { Cholesterol } \\
(\mathbf{m g} / \mathbf{d l})\end{array}$ & $\begin{array}{l}\text { Blood High } \\
\text { Density } \\
\text { Lipoprotein } \\
(\mathbf{m g} / \mathbf{d l})\end{array}$ & $\begin{array}{l}\text { Blood Low } \\
\text { Density } \\
\text { Lipoprotein } \\
(\mathbf{m g} / \mathbf{d l})\end{array}$ & $\begin{array}{l}\text { Blood } \\
\text { Triglyceride } \\
\text { (mg/dl) }\end{array}$ & $\begin{array}{l}\text { Blood } \\
\text { Glucose } \\
\text { (mg/dl) }\end{array}$ \\
\hline $\begin{array}{l}\text { Females } \\
\text { Mean }\end{array}$ & 163.6 & 64.3 & 78.5 & 108.9 & 89.5 \\
S.D. & 33.8 & 17.7 & 26.7 & 54.9 & 15.9 \\
Males & & & & & \\
Mean & 148.7 & 51.2 & 77.4 & 111.7 & 90.6 \\
S.D. & 31.4 & 13.7 & 31.1 & 116.3 & 12.2 \\
\hline $\begin{array}{l}\text { Grand Totals } \\
\text { Mean }\end{array}$ & 157.00 & 58.4 & 78.0 & 110.2 & 90.0 \\
S.D. & 33.6 & 17.3 & 28.7 & 87.7 & 14.4 \\
\hline
\end{tabular}


Table 3. Distribution of Total Cholesterol by Sex $(n=464)$

\begin{tabular}{|c|c|c|c|c|c|}
\hline & $\begin{array}{l}\text { Number of } \\
\text { Subjects by } \\
\text { Cholesterol } \\
\text { Classification }\end{array}$ & $\begin{array}{l}\text { Average of } \\
\text { Blood } \\
\text { Cholesterol } \\
\text { values } \\
(\mathrm{mg} / \mathrm{dl}) \\
\end{array}$ & $\begin{array}{l}\text { Standard } \\
\text { Deviation of } \\
\text { Blood } \\
\text { Cholesterol } \\
\text { values } \\
(\mathrm{mg} / \mathrm{dl}) \\
\end{array}$ & $\begin{array}{l}\text { Percent } \\
\text { Distribution } \\
\text { of } \\
\text { Cholesterol } \\
\text { by Sex } \\
\end{array}$ & $\begin{array}{l}\text { Percent } \\
\text { Distribution } \\
\text { of } \\
\text { Cholesterol } \\
\text { across all } \\
\text { Subjects }\end{array}$ \\
\hline Females & 257 & 163.6 & 33.8 & $57.7 \%$ & $57.7 \%$ \\
\hline Desirable & 224 & 155.2 & 27.1 & $82.7 \%$ & $47.7 \%$ \\
\hline $\begin{array}{l}\text { Borderline } \\
\text { High }\end{array}$ & 31 & 219.3 & 9.2 & $16.2 \%$ & $9.3 \%$ \\
\hline High & 2 & 250.0 & 5.7 & $1.2 \%$ & $0.7 \%$ \\
\hline Males & 207 & 148.7 & 31.4 & $42.3 \%$ & $42.3 \%$ \\
\hline Desirable & 196 & 144.0 & 24.5 & $91.7 \%$ & $38.8 \%$ \\
\hline $\begin{array}{l}\text { Borderline } \\
\text { High }\end{array}$ & 8 & 223.8 & 11.9 & $5.8 \%$ & $2.5 \%$ \\
\hline High & 3 & 256.0 & 22.6 & $2.5 \%$ & $1.1 \%$ \\
\hline Grand Total & 464 & 157.00 & 33.6 & $100.0 \%$ & $100.0 \%$ \\
\hline
\end{tabular}


Table 4. Distribution of High-Density Lipoprotein Cholesterol by Sex $(n=464)$

\begin{tabular}{|c|c|c|c|c|c|}
\hline & $\begin{array}{l}\text { Number of } \\
\text { Subjects by } \\
\text { HDL } \\
\text { Classification }\end{array}$ & $\begin{array}{l}\text { Average of } \\
\text { Blood HDL } \\
\text { values } \\
(\mathbf{m g} / \mathbf{d l})\end{array}$ & $\begin{array}{l}\text { Standard } \\
\text { Deviation of } \\
\text { HDL } \\
\text { Cholesterol } \\
\text { values } \\
\text { (mg/dl) }\end{array}$ & $\begin{array}{l}\text { Percent } \\
\text { Distribution } \\
\text { of HDL by } \\
\text { Sex }\end{array}$ & $\begin{array}{l}\text { Percent } \\
\text { Distribution } \\
\text { of HDL } \\
\text { across all } \\
\text { Subjects }\end{array}$ \\
\hline Females & 257 & 64.3 & 17.7 & $61 \%$ & $61 \%$ \\
\hline Optimal & 155 & 75.2 & 11.8 & $71 \%$ & $43 \%$ \\
\hline Suboptimal & 102 & 47.7 & 10.7 & $29 \%$ & $18 \%$ \\
\hline Males & 207 & 51.2 & 13.7 & $39 \%$ & $39 \%$ \\
\hline Optimal & 51 & 69.6 & 8.7 & $33 \%$ & $13 \%$ \\
\hline Suboptimal & 156 & 45.2 & 8.8 & $67 \%$ & $26 \%$ \\
\hline Grand Total & 464 & 58.4 & 17.3 & $100 \%$ & $100 \%$ \\
\hline
\end{tabular}


Table 5. Distribution of Low-Density Lipoprotein Cholesterol by Sex $(n=464)$

\begin{tabular}{llllll}
\hline & $\begin{array}{l}\text { Number of } \\
\text { Subjects by } \\
\text { LDL } \\
\text { Classification }\end{array}$ & $\begin{array}{l}\text { Average of } \\
\text { Blood LDL } \\
\text { values } \\
\text { (mg/d) }\end{array}$ & $\begin{array}{l}\text { Standard } \\
\text { Deviation of } \\
\text { LDL values } \\
\text { (mg/dl) }\end{array}$ & $\begin{array}{l}\text { Percent } \\
\text { Distribution } \\
\text { of LDL by } \\
\text { Sex }\end{array}$ & $\begin{array}{l}\text { Percent } \\
\text { Distribution } \\
\text { of LDL } \\
\text { across all } \\
\text { Subjects }\end{array}$ \\
\hline Females & 257 & 78.5 & 26.7 & $56 \%$ & $56 \%$ \\
$\quad$ Optimal & 212 & 69.6 & 19.1 & $73 \%$ & $41 \%$ \\
Above Optimal & 35 & 113.6 & 8.7 & $20 \%$ & $11 \%$ \\
Borderline High & 9 & 141.8 & 6.5 & $6 \%$ & $4 \%$ \\
High & 1 & 164.0 & 0.0 & $1 \%$ & $0 \%$ \\
\hline Males & 207 & 77.4 & 31.1 & $44 \%$ & $44 \%$ \\
Optimal & 173 & 67.3 & 17.8 & $73 \%$ & $32 \%$ \\
Above Optimal & 23 & 111.3 & 7.9 & $16 \%$ & $7 \%$ \\
Borderline High & 5 & 135.8 & 3.9 & $4 \%$ & $2 \%$ \\
High & 4 & 170.3 & 5.0 & $4 \%$ & $2 \%$ \\
Very High & 2 & 230.5 & 29.0 & $3 \%$ & $1 \%$ \\
\hline Grand Total & 464 & 78.0 & 28.71 & $100 \%$ & $100 \%$ \\
\hline
\end{tabular}


Table 6. Distribution of Triglycerides by Sex $(n=464)$

\begin{tabular}{|c|c|c|c|c|c|}
\hline & $\begin{array}{l}\text { Number of } \\
\text { Subjects by } \\
\text { Triglyceride } \\
\text { Classification }\end{array}$ & $\begin{array}{l}\text { Average of } \\
\text { Blood } \\
\text { Triglyceride } \\
\text { values } \\
(\mathrm{mg} / \mathrm{dl})\end{array}$ & $\begin{array}{l}\text { Standard } \\
\text { Deviation of } \\
\text { Triglyceride } \\
\text { values (mg/d) }\end{array}$ & $\begin{array}{l}\text { Percent } \\
\text { Distribution } \\
\text { of } \\
\text { Triglyceride } \\
\text { by Sex } \\
\end{array}$ & $\begin{array}{l}\text { Percent } \\
\text { Distribution } \\
\text { of } \\
\text { Triglyceride } \\
\text { across all } \\
\text { Subjects } \\
\end{array}$ \\
\hline Females & 257 & 108.9 & 54.9 & $55 \%$ & $55 \%$ \\
\hline Desirable & 222 & 92.4 & 29.9 & $73 \%$ & $40 \%$ \\
\hline Borderline High & 20 & 173.1 & 14.2 & $12 \%$ & $7 \%$ \\
\hline High & 15 & 267.4 & 60.6 & $14 \%$ & $8 \%$ \\
\hline Males & 207 & 111.7 & 116.3 & $45 \%$ & $45 \%$ \\
\hline Desirable & 176 & 87.2 & 26.9 & $66 \%$ & $30 \%$ \\
\hline Borderline High & 17 & 170.1 & 14.2 & $13 \%$ & $6 \%$ \\
\hline High & 12 & 233.8 & 24.5 & $12 \%$ & $5 \%$ \\
\hline Very High & 2 & 1040.5 & 764.4 & $9 \%$ & $4 \%$ \\
\hline Grand Total & 464 & 110.2 & 87.7 & $100 \%$ & $100 \%$ \\
\hline
\end{tabular}


Table 7. Distribution of Blood Glucose by Sex $(n=464)$

\begin{tabular}{llllll}
\hline & $\begin{array}{l}\text { Number of } \\
\text { Subjects by } \\
\text { Glucose } \\
\text { Classification }\end{array}$ & $\begin{array}{l}\text { Average of } \\
\text { Blood Glucose } \\
\text { values (mg/d) }\end{array}$ & $\begin{array}{l}\text { Standard } \\
\text { Deviation of } \\
\text { Glucose } \\
\text { values } \\
\text { (mg/d) }\end{array}$ & $\begin{array}{l}\text { Percent } \\
\text { Distribution } \\
\text { of Glucose } \\
\text { by Sex }\end{array}$ & $\begin{array}{l}\text { Percent } \\
\text { Distribution } \\
\text { of Glucose } \\
\text { across all } \\
\text { Subjects }\end{array}$ \\
\hline Females & 257 & 89.5 & 15.9 & $55 \%$ & $55 \%$ \\
Normal & 226 & 85.9 & 9.0 & $84 \%$ & $46 \%$ \\
Prediabetes & 26 & 106.5 & 7.0 & $12 \%$ & $7 \%$ \\
Diabetic & 5 & 164.4 & 42.5 & $4 \%$ & $2 \%$ \\
\hline Males & 207 & 90.6 & 12.3 & $45 \%$ & $45 \%$ \\
Normal & 165 & 86.7 & 10.0 & $76 \%$ & $34 \%$ \\
Prediabetes & 41 & 105.0 & 5.9 & $23 \%$ & $10 \%$ \\
Diabetic & 1 & 138.0 & 0.0 & $1 \%$ & $<1 \%$ \\
\hline Grand Total & 464 & 90.0 & 14.4 & $100 \%$ & $100 \%$ \\
\hline
\end{tabular}


Table 8. Distribution of Subjects with Metabolic Syndrome Based on Number of Risk Factors $(\mathrm{n}=464)$

\begin{tabular}{|c|c|c|}
\hline $\begin{array}{l}\text { Number of } \\
\text { Metabolic } \\
\text { Syndrome Risk } \\
\text { Factors }\end{array}$ & $\begin{array}{l}\text { Number of } \\
\text { Subjects with } \\
\text { Metabolic } \\
\text { Syndrome } \\
\text { Risk Factors }\end{array}$ & $\begin{array}{l}\text { Percent } \\
\text { Distribution of } \\
\text { Subjects with } \\
\text { Metabolic Risk } \\
\text { Factors }\end{array}$ \\
\hline $\mathbf{0}$ & 272 & $59 \%$ \\
\hline 1 & 139 & $30 \%$ \\
\hline 2 & 43 & $9 \%$ \\
\hline 3 & 7 & $2 \%$ \\
\hline 4 & 2 & $<1 \%$ \\
\hline 5 & 1 & $<1 \%$ \\
\hline Grand Total & 464 & $100 \%$ \\
\hline
\end{tabular}


Table 9. Distribution of Subjects by Sex with Metabolic Syndrome Based on Number of Risk Factors $(n=464)$

\begin{tabular}{lll}
\hline $\begin{array}{l}\text { Number of } \\
\text { Metabolic } \\
\text { Syndrome Risk }\end{array}$ & $\begin{array}{l}\text { Number of } \\
\text { Subjects with } \\
\text { Metabolic } \\
\text { Syndrome } \\
\text { Risk Factors }\end{array}$ & $\begin{array}{l}\text { Percent } \\
\text { Distribution of } \\
\text { Subjects with } \\
\text { Metabolic Risk } \\
\text { Factors }\end{array}$ \\
\hline Females & 257 & $55 \%$ \\
$\mathbf{0}$ & 153 & $60 \%$ \\
$\mathbf{1}$ & 81 & $32 \%$ \\
$\mathbf{2}$ & 18 & $7 \%$ \\
$\mathbf{3}$ & 3 & $1 \%$ \\
$\mathbf{4}$ & 2 & $1 \%$ \\
$\mathbf{5}$ & 0 & $<1 \%$ \\
\hline Males & 207 & $45 \%$ \\
$\mathbf{0}$ & 119 & $57 \%$ \\
$\mathbf{1}$ & 58 & $28 \%$ \\
$\mathbf{2}$ & 25 & $12 \%$ \\
$\mathbf{3}$ & 4 & $2 \%$ \\
$\mathbf{5}$ & 1 & $0.8 \%$ \\
\hline Grand Total & $\mathbf{4 6 4}$ & $\mathbf{1 0 0 \%}$ \\
\hline
\end{tabular}


Table 10. Metabolic Syndrome Risk Factors in College Students $(n=464)$

\begin{tabular}{|c|c|c|c|}
\hline \multirow[b]{2}{*}{ Metabolic Syndrome Risk Factor } & \multicolumn{3}{|c|}{ Prevalence of Risk Factors (\%) } \\
\hline & $\begin{array}{l}\text { Females } \\
(\mathbf{n}=\mathbf{2 5 7})\end{array}$ & $\begin{array}{l}\text { Males } \\
(\mathrm{n}=\mathbf{2 0 7})\end{array}$ & $\begin{array}{l}\text { Combined } \\
(n=464)\end{array}$ \\
\hline Low HDL & 17.1 & 17.4 & 17.2 \\
\hline Elevated Triglycerides & 13.7 & 15.0 & 14.2 \\
\hline Elevated Blood Glucose & 9.3 & 12.1 & 10.6 \\
\hline Increased Waist Circumference & 9.0 & 6.8 & 8.0 \\
\hline Elevated Blood Pressure Response & 3.1 & 9.2 & 5.8 \\
\hline Increased Diastolic Blood Pressure Response & 2.3 & 4.9 & 3.5 \\
\hline Increased Systolic Blood Pressure Response & 1.2 & 6.3 & 3.5 \\
\hline
\end{tabular}


Table 11. Relationship Between Cardiovascular HRA and Blood Lipids/Glucose $(n=464)$

\begin{tabular}{|c|c|c|c|c|c|c|c|c|}
\hline $\begin{array}{l}\text { Cardiovascular } \\
\text { Heart Disease } \\
\text { Health Risk } \\
\text { Appraisal } \\
\text { Classification } \\
\end{array}$ & $\begin{array}{l}\text { Number of } \\
\text { Subjects by } \\
\text { HRA } \\
\text { Classification }\end{array}$ & $\begin{array}{l}\text { Average of } \\
\text { HDL } \\
(\mathrm{mg} / \mathrm{dl})\end{array}$ & $\begin{array}{l}\text { Average of } \\
\mathrm{LDL} \\
(\mathrm{mg} / \mathrm{dl})\end{array}$ & $\begin{array}{l}\text { Average of } \\
\text { Cholesterol } \\
\text { (mg/dl) }\end{array}$ & $\begin{array}{l}\text { Average of } \\
\text { Total/HDL } \\
\text { Ratio } \\
\end{array}$ & $\begin{array}{l}\text { Average of } \\
\text { Triglycerides } \\
\text { (mg/dl) }\end{array}$ & $\begin{array}{l}\text { Average } \\
\text { of } \\
\text { Glucose } \\
\text { (mg/dl) }\end{array}$ & $\begin{array}{l}\text { Average } \\
\text { Number } \\
\text { of } \\
\text { Metabolic } \\
\text { Syndrome } \\
\text { Risk } \\
\text { Factors } \\
\end{array}$ \\
\hline Low & 378 & 60.7 & 74.5 & 155.3 & 2.7 & 108.0 & 89.2 & 0.4 \\
\hline Moderate High & 25 & 43.1 & 99.5 & 159.2 & 4.0 & 136.3 & 91.8 & 1.5 \\
\hline High & 11 & 47.3 & 108.8 & 188.4 & 5.0 & 161.7 & 113.4 & 2.2 \\
\hline Grand Total & 461 & 58.4 & 78.0 & 157.0 & 2.9 & 110.2 & 90.0 & 0.6 \\
\hline
\end{tabular}


Table 12. Longitudinal Analysis of Metabolic Syndrome Risk Factors in College Students ( $\mathrm{n}=464)$

\begin{tabular}{llll}
\hline & \multicolumn{3}{l}{ Prevalence of Risk Factors (\%) } \\
Metabolic Syndrome Risk Factor & $\begin{array}{l}\mathbf{2 0 2 0} \text { Data } \\
\text { analysis } \\
\text { (n= 464) }\end{array}$ & $\begin{array}{l}\mathbf{2 0 1 8} \text { Data } \\
\text { analysis } \\
(\mathbf{n}=\mathbf{7 0})\end{array}$ & $\begin{array}{l}\mathbf{2 0 1 4} \text { Data } \\
\text { analysis } \\
\text { (n= 141) }\end{array}$ \\
\hline Low HDL & 17.2 & 17.1 & 16.5 \\
Elevated Triglycerides & 14.2 & 21.4 & 11.5 \\
Elevated Blood Glucose & 10.6 & 18.6 & 9.8 \\
Increased Waist Circumference & 8.0 & 2.9 & 8.3 \\
Elevated Blood Pressure Response & 5.8 & 8.6 & 5.0 \\
Increased Diastolic Blood Pressure Response & 3.5 & 5.7 & 4.0 \\
Increased Systolic Blood Pressure Response & 3.5 & 5.7 & 2.5 \\
\hline
\end{tabular}




\section{References}

Alamari, H. (2019). Assessing healthy nutrition awareness among college students and the role of health education in promotion. College Student Journal, 53(3), 360-368.

Alshuwaiyer, G., \& Taylor, E. L. (2014). Awareness of heart disease among female college students. American Journal of Health Studies, 29(4), 287-301.

Appiah, D., \& Capistrant, B. D. (2017). Cardiovascular disease risk assessment in the United States and low- and middle-income countries using predicted heart/vascular age.

Scientific Reports, 7, 16673(2017). doi:10.1038/s41598-017-16901-5

Arts, J, Fernandez, M. L., \& Lofgren, I. E. (2014). Coronary heart disease risk factors in college students, Advances in Nutrition, Volume 5, Issue 2, March 2014, Pages 177187, https://doi.org/10.3945/an.113.005447

Center for Disease Control and Prevention. (2019). Heart disease facts. Retrieved February 2, 2020, from https://www.cdc.gov/heartdisease/facts.htm

Filler, N.P. (2018). Comparing the prevelance of metabolic syndrome risk factors in college age students from 2014 to 2018. (2018.) Unpublished research

Mahan, K. L., \& Raymond, J. L. (2017). Food \& the nutrition care process (14 ${ }^{\text {th }}$ ed.). St. Louis, MO: Elsevier.

McArdle, W., Katch, F., \& Katch, V.(2015). Essential of exercise physiology ( $8^{\text {th }}$ ed.). Wolters Kluwer. 
McMahan, S. (2007). Cardiovascular disease risk perception and knowledge: A comparison of Hispanic and white college students in a Hispanic-serving institution. Journal of Hispanic Higher Education, 6(1), 5-18. https://doiorg.libproxy.lib.ilstu.edu/10.1177/1538192706294750

Melnyk, J. A., Panza, G., Zaleski, A., \& Taylor, B. (2015). Awareness and knowledge of cardiovascular risk through blood pressure and cholesterol testing in college freshmen. American Journal of Health Education, 46(3), 138-143.

Micinski, N. R, Barnas, J.L., Dennis, K.D. , Lierman A., Wheatley, L.V. , Brown D. D. (2013). Prevalence of metabolic syndrome risk factors in college students. Medicine and Science in Sports and Exercise. Medicine and Science in Sports and Exercise, 45(5S): (abstract \#637).

Nazar, M., Khan, A.S., Kumar, R. \& Hafeez, A. (2019). Effectiveness of health literacy intervention on cardiovascular diseases among university students of Pakistan. $B M C$ Health Services Research, 1, 1. https://doi-org.libproxy.lib.ilstu.edu/10.1186/s12913-019$4348-\mathrm{y}$

Porth, C., \& Matfin, G., (2009). Pathophysiology: concepts of altered health states ( $8^{\text {th }}$ edition). Wolters Kluwer.

Ramey, S. L. (2005). Assessment of health perception, spirituality and prevalence of cardiovascular disease risk factors within a private college cohort. Pediatric Nursing, 31(3), 222-231. 
Robinson, R., Roberson, K. B., Onsomu, E. O., Dearman, C., Nicholson, Y. M., Price, A. A., \& Winfield, V. D. (2019). Perceived risk of cardiovascular disease and health behaviors in black college students. Journal of Best Practices in Health Professions Diversity: Education, Research \& Policy, 12(1), 24-45.

Sarpong, D. F., Curry, I.Y. \& Williams, M. (2017). Assessment of knowledge of critical cardiovascular risk indicators among college students: Does stage of education matter? International Journal of Environmental Research and Public Health, 3, 250. https://doi-org.libproxy.lib.ilstu.edu/10.3390/ijerph14030250

Thiagalingam, U., Priya, V. V., \& Gayathri, R. (2019). Awareness on the risk factors of cardiovascular disease among college students. Drug Invention Today, 11(9), 2211-2213.

Tran, D.-M. T., Zimmerman, L. M., Kupzyk, K. A., Shurmur, S. W., Pullen, C. H., \& Yates, B. C. (2017). Cardiovascular risk factors among college students: Knowledge, perception, and risk assessment. Journal of American College Health, 65(3), 158-167. https://doiorg.libproxy.lib.ilstu.edu/10.1080/07448481.2016.1266638 


\section{CHAPTER II: EXTENDED REVIEW OF LITERATURE}

An estimated 81 million adult Americans have one or more types of cardiovascular disease. Cardiovascular disease remains as the number one cause of death for men and women in the United States. Worldwide, eighteen million deaths per year are attributed to cardiovascular disease (6). Heart disease costs the United States about \$219 billion each year from 2014 to 2015. This includes the cost of health care services, medicines, and lost productivity due to death (5). Literature indicates that 80 percent of cardiovascular disease diagnoses could have been prevented by lifestyle and behavioral changes (3).

Because previous research has correlated factors that may cause cardiovascular disease over time, one can conclude that educating and implementing lifestyle interventions at a younger age is the most ideal way to prevent cardiovascular disease. With college-age students, some of their behaviors may contribute to their risk. With their busy lives, onset of independence, and attitudes, some may not have the time, desire, or awareness of behaviors to implement a lifestyle that could reduce their risk later in life.

More than one-half of young adults aged 18-24 years old have at least one coronary heart disease risk factor and nearly one-quarter have advanced atherosclerotic lesions. Most young adults are not screened and/or are unaware of their risk (Art, J., Fernandez, M., Lofgren, I., 2014). The prevalence continues to remain high. The purpose of this review is to explore the various research surrounding awareness and knowledge of cardiovascular disease risk in collegeage students.

Alshuwaiyer, G. and Taylor E. L. sought to assess the knowledge, awareness, and perceptions related to cardiovascular disease of 315 female college students between the ages of 
18-64 years old from the University of Oklahoma. The participants complete an online survey that assessed trends in awareness and knowledge of heart disease, along with preventative behaviors in women. Various demographic information was obtained, in addition to height, weight, household living arrangements, and health insurance information was collected. The survey included other questions regarding the participants overall health condition and their physical and emotion health status. The researchers asked questions regarding the leading cause of death among women. Other questions were related to the knowledge of heart disease including warning signs of heart attack, barriers around leading a healthy lifestyle, and preventative actions that promote cardiovascular health.

All data was entered into and analyzed using SPSS. Data was presented as percentages and means with standard deviations. Data was compared by ethnicity, health insurance type, and grade level. Upon their results, many students were white, never, married, senior students, and between the ages of $18-27$ years old. The researchers found that $54 \%$ of the participants responded as inactive with $26 \%$ being 20 pounds over their ideal weight and $37.4 \%$ having a family history of stroke. In addition, $42.6 \%$ stated that they were in "good" physical condition and $37.9 \%$ had "good" emotional health.

In relation to cardiovascular disease, the researchers found that $59.6 \%$ of students had reported that cardiovascular disease is among the top three leading causes of death. When the students were asked about how informed they were about heart disease, $32 \%$ reported not at all informed with $29 \%$ saying that they lead a heart healthy lifestyle and do not face any barriers that stop them from taking preventative actions. Of the various barriers they displayed, $48.2 \%$ cited "being too stressed to do the things that need to be done." They concluded that the level of 
knowledge with women has increased in the last decade but is still below the desirable level. They emphasized the importance of reaching youth in universities to continue increasing heart disease awareness.

Similarly, McMahan, S. conducted a study in 2007 that pointed out the awareness in college students of the leading cause of death in addition to other factors. The researcher sought to assess cardiovascular disease risk perception and knowledge while comparing 124 Hispanic students and 153 Caucasian college students between the ages of 18 to 25 in a Hispanic institution. The researcher addressed the difference between clear health conditions between the Hispanic population and the Caucasian population. In addition, the researchers identified the lifestyle behaviors and genetic predispositions with college students. Because cardiovascular disease is a disease of slow development, they pointed out the importance of prevention at a younger age as it could protect from the onset of the disease or diminish the progression. The students were enrolled in various sections of an introductory personal health class at a western state university.

The researcher used a questionnaire to assess the differences in risk perception. The researcher contacted 8 professors from personal health courses to give the questionnaire in their class. The questionnaire consisted of 52 questions regarding demographics, perceived susceptibility, knowledge, and behavioral intention. The demographics section consisted of race, age, and class levels. The personal history included family history, rating of their health status, diet, physical activity, weight, body mass index, rating of the health status of their parents, and if they were ever informed of cardiovascular disease risk. The perceived susceptibility section identified whether college students perceived themselves as susceptible to cardiovascular disease 
risk and the onset of the disease using a Likert scale of very likely to very unlikely. The knowledge section identified the background knowledge of cardiovascular disease asking open ended questions. The behavioral intention section identified behavior change using a Likert scale of very likely to unlikely. The question asked if they were ever informed of risk and how likely it would be that participants change their current lifestyle.

Upon their results, $21 \%$ of the participants identified a family history of cardiovascular disease. More Caucasian individuals had a greater family history risk. In terms of their health status, $28.1 \%$ of the students rated their health as excellent or very good, $50.9 \%$ rated their health as good, and $20.2 \%$ rated their health as fair or poor. More Hispanics rated their health as fair or poor than Caucasians. In terms of diet, $20.9 \%$ rated their diet as very healthy or healthy, $58.5 \%$ rated their diets as somewhat healthy, and $20.5 \%$ rated their diet as unhealthy or very unhealthy. Of the students who rated their diets as unhealthy, $25 \%$ were Hispanic and $14.4 \%$ were Caucasian. In terms of physical activity, $47.7 \%$ stated that they exercised 2-3 times per week, $65.3 \%$ stated that they exercised between 30 minutes to 1 hour, and $70 \%$ stated that they exercised at a moderate intensity level.

In terms of weight, $58.8 \%$ of students rated themselves as being the right weight, $31 \%$ rated themselves as being somewhat or very overweight, $9.4 \%$ rated themselves as being somewhat or very underweight, and .7\% did not answer it. More Hispanic students rated their weight as being somewhat overweight than Caucasian students. In terms of BMI, the ranges were between 16-25. In terms of being informed of cardiovascular disease risk, 91.7\% said no and $5.8 \%$ said yes. In terms of risk of cardiovascular disease risk compared to others, $50.5 \%$ rating 
themselves are very unlikely or unlikely to develop cardiovascular disease compared to others their age.

In terms of knowledge, $35 \%$ of participants chose cancer as the leading cause of death in the United States, $28.2 \%$ chose cardiovascular disease, and $24.2 \%$ chose accidents. Less than $12 \%$ chose diabetes, influenza, or chronic obstructive pulmonary disease and less than $5.2 \%$ did not answer. In terms of signs and symptoms, $35.5 \%$ chose chest pain, $30.3 \%$ chose shortness of breath, less than $25 \%$ indicated pain in upper body, and $28 \%$ said tiredness. In terms of riskreducing behaviors, the most chosen risk-reducing behaviors were to increase physical activity and eat for heart healthy. The third and fourth highest rated behaviors were to see doctor and stop smoking. More than 3 quarters of the participants reported that they would be very likely or likely to change their lifestyle if a doctor informed them that they are at risk. The researcher concluded that college students have limited knowledge regarding cardiovascular disease risk and Hispanic individuals are particularly at risk because of their higher risk of developing cardiovascular disease and obesity. They emphasized the importance of increased knowledge and awareness of signs, symptoms, and risk factors for cardiovascular disease as the disease has no geographic, gender, racial, or socioeconomic differentiation and remains a major health concern in the United States.

Robinson, R., Roberson, K. B., Onsomu, E. O., Dearman, C., Nicholson, Y. M., Price, A. A., \& Winfield, V. D. completed a study in 2019 that examined a specific race, like the last study discussed. They examined the relationship between perceived risk of cardiovascular disease and health behaviors. They recruited 14, Black race students that were between the ages of 18-25. There were no exclusion criteria. Self-identified non-black students were offered the opportunity 
to participate to avoid any perception of partiality. The students were recruited using a flyer distributed by an instructor during class, email, and the learning management system.

Perceived cardiovascular disease risk was measured by the Perceived Risk of Heart Disease Scale. The researchers used a 20 -item instrument that asks general questions with a Likert scale response. These questions addressed dread risk and aligned with perceived risk. The actual disease risk was defined as conditions that escalate risk of disease development, including age, gender, family history, hypertension, diabetes, smoking, obesity, and overweight. It was measured using the Healthy Heart Score Tool to validate cardiovascular risk predictions based on modifiable risk factors. Following the survey, the participants reviewed their personal risk score ranging from low, moderate, to high.

The Health-Promoting Lifestyle Profile II was used to measure health promoting behavior, conceptualized as a multidimensional pattern of self-initiated actions and perceptions that serve to maintain or enhance the individual's level of wellness, self-actualization and fulfillment. It was a 52-item scale with a 4-point response to measure frequency of selfpromoting behaviors with health responsibility, physical activity, nutrition, spiritual growth, interpersonal relations, and stress management. Data analysis included the use of descriptive statistics and bivariate correlation to examine categorical variables. Spearman rank correlation was used to examine the relationship between perceived risk and health promoting behaviors.

Upon their results, they found that 4 out of the 14 responded with thinking they will get heart disease in the next ten years and 10 responded with thinking they are healthy and will not get the disease. They found that $71.43 \%$ agreed they have no control over the disease process with $92.86 \%$ agreeing that they are aware of the disease outcomes and consequences. They found 
that $3 \%$ of the participants had ideal risk for cardiovascular disease, $2 \%$ were in the slightly elevated category, $6 \%$ had moderately high risk, and 3\% had high risk. In terms of the healthpromoting behaviors, they found that 3 responded with neve choosing healthy options and 8 indicated that only sometimes did they choose the healthy options. For physical activity, 3 participants reported that they never follow an exercise program, 7 indicated sometimes, 3 indicated often, and 1 indicated routinely. Responses to questions concerning health responsibility revealed that 2 never, 6 sometimes, 5 often, and 1 routinely asked for information from health professionals about how to take good care of themselves. In terms of reading or watching TV programs about improving health, 7 responded never, 3 sometimes, and 4 often do so. In terms of interpersonal relations, 8 indicated that they often spent time with close friends.

In relation to stress management and getting enough sleep, 3 said never, 6 sometimes, 3 often, and 2 routinely. In terms of practicing relaxation or meditation for 15-20 minutes daily, 4 said never, 6 sometimes, 3 often, and 1 routinely. In terms of spiritual growth, 8 reported that they routinely believe that they have a purpose in life. They concluded that participants may receive a low risk of developing cardiovascular disease but are at an increased risk due to lifestyle factors such as physical inactivity, smoking, unhealthy diet choices, and stress. They identified the importance of healthcare professionals and educators coming together to design, implement, and evaluate health behavioral change interventions for college students to reduce and manage their risk among future generations.

Diving deeper into spiritual growth and spiritual components, Ramey, S.L. completed a study that incorporated spirituality components. The researcher conducted a study that assessed the health perception, spirituality, and prevalence of cardiovascular disease risk factors within a 
private college cohort. They identified the increased prevalence of several cardiovascular disease risk factors and the impact that spiritual, emotional, and physical well-being can make on one's risk. The researchers recruited 644 students at a small private college in Iowa. Of their sample, 256 were female and 146 were male. Moreover, 93\% were Caucasian, $2.7 \%$ were African American, 2.0\% were Asian, and 2.3\% were other.

They sent out survey's via campus mail, at college meetings, and by direct mail to the neighbors living adjacent to the college to observe the general Iowa population. This survey consisted of 50 questions, which was developed from the Behavioral Risk Factor Surveillance System (BRFSS). They included questions verbatim from the BRFSS, 14 questions about stress from the Perceived Stress Scale, and 4 questions regarding perceptions of spirituality from the Evangelical Luther Colleges of America. Their variables were cardiovascular disease, stress, diabetes, cholesterol, hypertension, physical activity, body mass index, and age. Their data analysis included comparing the prevalence of cardiovascular disease and cardiovascular disease risk factors between the college group and Iowa's population. In addition, they observed qualitative data by comparing these results with existing findings of epidemiology, behavioral research, quantitative survey results, and administrative perspectives.

They found that spirituality was most often defined as happiness with self and associated with a sense of peace. Gossiping, mean-spirited behaviors, overwork, and judgmental behavior were identified by students as detriments to their spirit. The students identified that health encompasses mind, body, and spiritual components. In terms of health risk and perception to stress, $90 \%$ of the students listed their health as good to excellent. In relation to cardiovascular disease risk factors, $11.7 \%$ had hypertension, $11.9 \%$ had hypercholesterolemia, $2.2 \%$ had 
diabetes, $11.4 \%$ use tobacco, $23.4 \%$ were considered overweight, $10 \%$ were considered obese, $1.7 \%$ had cardiovascular disease, and $9.0 \%$ participated in no physical activity. Among the general Iowa population, $25.5 \%$ had hypertension, $30.4 \%$ had hypercholesterolemia, $5.7 \%$ had diabetes, $23.2 \%$ used tobacco, $38.5 \%$ were considered overweight, $21.5 \%$ were considered obese, $4.1 \%$ had cardiovascular disease, and $25.9 \%$ participated in no physical activity.

Within the student sub-group, $47.0 \%$ reported wanting to lose weight and $57.0 \%$ reported using physical activity to achieve desired weight. In the student sub-group, $4 \%$ self-reported having been told their cholesterol was increased and 11\% reported "don't know/not sure." In addition, a statistically significant association between increased cholesterol levels and stress was found. These results allowed the researchers to conclude that students perceived high levels of stress, a statistically significant associated between stress and high cholesterol was found, and risk is less than in the general Iowa population. In addition, the researchers highlighted the importance of considering the spiritual component of health when assessing cardiovascular disease and health risk due to the findings of consistent rates of ideal body weight and lower prevalence of hypertension in those who rated themselves higher on the spiritual well-being scale. Overall, they encouraged health care providers to educate more on all aspects for prevention.

Pursuing this relationship between lifestyle factors and diseases further, Alamari, H. conducted a study in 2019 that observed the level of healthy nutrition awareness between college students and its effects on their health. Although this study does not directly target cardiovascular disease, it adds to the idea of lifestyle factors and awareness and knowledge of its effects. The researcher conducted a nutrition questionnaire between 340 undergraduate students 
at Kuwait University. They were between the ages of 18-26. The most frequent observed were female. The questionnaire consisted of three sections. The first sections observed demographic information such as gender, age, level of education and college of study. The second section measured differences in perception among college students regarding awareness of healthy nutrition. The third section regarded the role of health education in promoting healthy nutrition between college students. Cronbach's alpha coefficients were calculated for healthy nutrition and health education.

Upon their results, they found that responses stating "performing daily exercise increase the body ability to prevent overweight" had a mean of 4.25 and standard deviation of .93 . The response, "food additives and chemicals added to food, are related to cancer" had a mean of 4.23 and a standard deviation of 1.21 . The response "dairy products are rich with vitamin $\mathrm{D}$, calcium and phosphorus, it helps the healing process of fractured bones" had a mean of 4.15 and a standard deviation of 1.02. The response "eating healthy food helps prevent the spread of overweight and obesity and is very important for a person's overall health" had a mean of 4.06 and a standard deviation of 1.05 . The response "fruits and vegetables are rich with vitamins, minerals and fibers" had a mean of 4.00 and a standard deviation of 1.02 .

The response "protein deficiency causes malnutrition diseases" had a mean of 3.88 and a standard deviation of 1.38. The response "bread and beans food group contain a high percentage of carbohydrates and it's a high source of energy" had a mean of 3.59 and a standard deviation of 1.32. The response "freezing food help preserve it for longer time" had a mean of 3.26 and a standard deviation of 1.49. The response "vitamin A deficiency cause eyesight weakness" had a mean of 2.63 and a standard deviation of 1.42. The response "people with high cholesterol 
should eat less fatty food" had a mean of 2.61 and a standard deviation of 1.41. The response "vitamin D, calcium, and phosphorus deficiency are the main cause for bone diseases" had a mean of 2.32 and a standard deviation of 1.62. Lastly, the response "vitamin B12 helps prevent blood anemia" had a mean of 2.22 and a standard deviation of 1.50 .

The researcher concluded that the data revealed that a high percentage of college students are not aware about the health problems and the risk factors associated with unhealthy eating habits. Most of the students were found according to their gender, age, level of study, and major. Statistical Analysis using a t-test revealed that there were significant differences between nutrition awareness among students with male students having a higher level of awareness than their counterparts in all aspects. Most students agreed that health education plays an important role in promoting healthy nutrition among them.

Moreover, several studies were found that contributed to the conclusion of the author in the previous studies mentioned about the importance of education and the role it plays. In 2015, Melnyk, J. A., Panza, G, Zaleski, A., and Taylor, B. conducted a study that observed the effectiveness of assessment of blood pressure and cholesterol screening and cardiovascular disease knowledge testing. In addition, they sought to determine whether an intervention that both tested each student's blood pressure and blood lipids and administered a short one-on-one standard 15-minute educational session with their individualized results translated into an improvement in their knowledge about heart disease. They wanted to determine whether this session resulted in measurable change in their diet and/or physical activity levels. The researchers recruited 75 freshman students at 3 major universities, with 31 completing the full 
study. The mean age was $18-24$ years old with 17 being women and 14 being men. The subjects had completed 3 study visits.

On the first visit, the students completed three questionnaires, gave a blood sample, and had their blood pressure measured. The first questionnaire consisted of a 30-item Heart Disease Knowledge Questionnaire to assess knowledge and risk factors. These domains included diet, risk factors, medical, epidemiological, and symptoms. The second questionnaire was the Paffenbarger Physical Activity Questionnaire that determined baseline physical activity. The third questionnaire was the Block Fat Screener Dietary Questionnaire that determined baseline diet patterns. Both the Paffenbarger Physical Activity Questionnaire and the Block Fat Screener Dietary Questionnaire were given to the participants on the first and last visit. For the collected blood sample, they obtained values for total cholesterol, high-density lipoprotein, low-density lipoprotein, and triglycerides.

The second visit was one month later, and it consisted of an educational awareness session that lasted approximately 15 -minutes. The participants received a standardized report regarding their cholesterol levels, blood pressure value, and literature describing where his or her values fell within normative guidelines. They gave out 3 other handouts describing cardiovascular disease risk factors, how to build a healthy plate, and physical activity recommendations and guidelines. Two months later, there was a third visit that repeated the physical activity and dietary questionnaire. The researchers completed a one-way analysis of variance between the Heart Disease Knowledge Questionnaire, the Paffenbarger Physical Activity Questionnaire, and the Block Fat Screener Dietary Questionnaire. The relationships between variables were assessed using multiple linear regression. 
Upon their results, they found that all means for blood cholesterol and blood pressure fell within normative values. Total cholesterol ranged from 95 to $209 \mathrm{mg} / \mathrm{dL}$ with 3 participants exceeding $200 \mathrm{mg} / \mathrm{dL}$, putting them at borderline risk. Values for high-density lipoprotein ranged between $26-87 \mathrm{mg} / \mathrm{dL}$ with 5 falling below the risk values. Values for low-density lipoprotein fell within the range of 32-131 mg/dL with one participant having a value greater than 140 $\mathrm{mg} / \mathrm{dL}$. Triglycerides ranged from 30-385 mg/dL with 3 having values greater than $200 \mathrm{mg} / \mathrm{dL}$. Systolic blood pressure ranged from $85-135 \mathrm{mmHg}$ and diastolic ranged from $50.5-85.5 \mathrm{mmHg}$ with 2 individuals having values greater than $85 \mathrm{mmHg}$.

When comparing the questionnaires, they were not significantly different between the time points. In addition, they found that the participants were relatively unknowledgeable about cardiovascular disease risk, with a mean score of 15.53 out of 30 on the Heart Disease Knowledge Questionnaire. These results allowed them to conclude that knowledge can be improved with a short periodization and general health education intervention. Moreover, they concluded that personalized feedback and general health education that provided knowledge to diet, physical activity, and normative values for blood pressure and cholesterol resulted in improved basic knowledge about cardiovascular disease risk factors.

To demonstrate the effectiveness of an educational piece further, Nazar, M., Khan, S. A., Kumar, R., \& Hafeez, A. completed a study in 2019 that looked at the effectiveness of health literacy intervention on cardiovascular diseases among university students of Pakistan. The researchers identified the burden of cardiovascular disease. They defined health literacy as the degree to which people can access, understand, appraise and communicate information to engage with demand of different health contexts in order to promote and maintain good health across the 
life course. The researchers wanted to look in Pakistan because studies have shown health literacy is lower than related poor health outcomes. The researchers recruited 115 undergraduate, non-medical students from a public university in Pakistan, but only 100 successfully completed the study.

The researchers took 2 measurements; they took one before and one after by interviewing the students on adopted, pretested, piloted, and validated tool. Pretesting was conducted by interviewing ten university students from the adjacent district. They used descriptive statistics for sociodemographic variables. Variables on hypertension had 12 questions with score $0-8$, stroke symptoms had 4 questions with score $0-8$, health literacy had 8 questions with score $0-53$, and preventative practice variables had 8 questions with scored 5-22. Frequencies and percentages were obtained for each question.

The researchers completed an education intervention consisted of a 90-minute session. The content included cardiovascular disease risk factors, epidemiology of cardiovascular disease, normal and high measurements of hypertension, cardiovascular disease complications, medications, epidemiology and symptoms of heart attack, symptoms of stroke and preventive practices about knowing their usual blood pressure. They also discussed use of salt and fat intake, physical activity and its frequency, and smoking habit of sample students and information seeking behavior.

Upon their results, they found that media was the dominant source of information regarding cardiovascular disease followed by friends, family, teachers, doctors, and other sources. The intervention had a positive result after the training on their knowledge in different variables. The mean baseline score was 31 , and it had increased to 41 in the post-test. The 
findings of this study showed low levels of awareness about hypertension, stroke, and cardiovascular disease and intervention showed a significant change after posttest assessment. The researchers concluded that health literacy is important in protecting from chronic disease, and their study has shown that mortality and morbidity by cardiovascular disease can be reduced by the effective awareness intervention in this population.

To further expand on the idea of the importance of education, Daniel F. Sarpong, India Y. Curry, \& Williams, M. conducted a study in 2017 that observed the assessment and knowledge of critical cardiovascular disease risk indicators among college students and if the level of education matters. The researchers pointed out the challenge for college-students to make the right choices and engage in risky behaviors. Moreover, they acknowledged current literature targeting this population as having a higher risk for cardiovascular than they may be aware of. The researchers recruited 223 college freshmen from Louisiana between the ages of 18-20. There were two groups of students. The first group was 133 second-semester freshman and the second group were 90 Professional Year 1 students.

The participants completed a pre-test survey to give them a number. All survey data was anonymous. The survey was administered in a group setting in selected sections of the Freshman Seminar II class or to students in the residential halls. The students in the residential halls were recruited by email. The survey included demographic information, knowledge of participant's health related values, and health behaviors. The health-related values that they looked at was glucose, cholesterol, blood pressure, and body mass index. The health behaviors that they observed were physical activity and diet. Two sample t-tests were used to assess the differences in subgroups. 
Upon their results, there were differences in gender, age, and race or ethnicity between the two groups. The Professional Year 1 students compared to freshmen had fewer females, fewer AAs, and were older. The overall percentage of the participants' knowledge was low. There were differences between Professional Year 1 students and freshman in terms of knowledge of total cholesterol, blood pressure, and percentage of participants with all four health indicators in normal range. In addition, a greater percentage of the Professional Years 1 students were aware of their blood pressure and BMI. On average, the Professional Year 1 students engaged in more physical activity and the freshman indicated that they maintained healthy diets.

Of the college freshman, $28 \%$ were knowledgeable of their blood pressure, $63 \%$ knew the normal range for normal range for blood pressure, $23 \%$ knew the normal range for BMI, and $64 \%$ stated that they maintained a healthy diet. Of the Professional Year 1 students, $46 \%$ were knowledgeable of their blood pressure, $74 \%$ knew the normal range for blood pressure, $39 \%$ knew the normal range for BMI, and 36\% stated that they maintained a healthy diet. Overall, the level of awareness of their health-related numbers was low for total cholesterol, blood glucose, blood pressure, and body mass index. In addition, less than one in every four students knew if their health indicators were within normal range. Although the Professional Year 1 students had higher scores than the freshman in terms of the four cardiovascular disease risk factor indicators, only the knowledge of one's blood pressure was significant. This suggests that the more educated students might have an advantage over the college freshman. The researchers concluded that college student's level of awareness of knowledge of their health-related numbers 
was very low and further research is required to understand the low level of awareness of critical health indicators among college students.

To further expand on the discussion of modifiable and nonmodifiable risk factors, Tran, D.M. T., Zimmerman, L. M., Kupzyk, K. A., Shurmur, S. W., Pullen, C. H., \& Yates, B. C. conducted a study in 2017, that observed the cardiovascular risk factors among college students and their knowledge, perception, and risk assessment. Specifically, they wanted to examine the modifiable and nonmodifiable cardiovascular disease risk factors and examine the relationships between knowledge, perceived susceptibility, perceived severity, and lifetime risk assessments. They identified the prevention and intervention strategies and goals that have been proposed to reduce cardiovascular disease mortality and morbidity, and they sought to show the relationship of that with young adults of the future. The researchers recruited 158 college students between the ages of 19 and 39, enrolled at a midwestern university. The average age was $24.33+/-4.6$ years, and $54.4 \%$ were male. They recruited by using flyers, health care staff at the university, and active recruitment by the principle investigator. Anyone who stated to the principal investigator that they had cardiovascular disease was excluded.

All participants completed a short questionnaire measuring demographic characteristics, personal health history, 2 questions regarding physical activity, and 3 questions regarding dietary habits. Height, weight, body mass index, blood pressure, and fasting or nonfasting blood serum for lipid profiles and glucose were obtained. The Heart Disease Fact Questionnaire was used to assess general knowledge of the participants in terms of cardiovascular disease risk factors. This questionnaire measures risk factors of family history, age, sex, smoking, physical activity, lipids, blood pressure, weight, and if the individual knew heart disease was present. The questions 
consisted of true or false questions with an option to select "I don't know." In addition, the Health Beliefs Related to Cardiovascular Disease questionnaire was used to assess perception of cardiovascular disease risk factors. This questionnaire consisted of 10 items with 2 subscales based on perceived susceptibility, and perceived severity. Responses to the questions were indicated on a 4-point Likert scale. Pooled Cohort risk equations were used to generate lifetime risk using the following risk factors: sex, age, race, total cholesterol, HDL cholesterol, systolic blood pressure, if they have received treatment for high blood pressure, if they have diabetes, and if they are a smoker.

Diabetes, overweight or obesity, hypertension, hyperlipidemia, and being a smoker were all measured quantitatively, except for smoking status because it was self-reported. When examining these, $47.5 \%$ had no cardiovascular disease risk, $36.1 \%$ had 1 risk factor, $13.9 \%$ had 2 risk factors, and $2.5 \%$ had 3 risk factors. Of the other risk factors, the most frequently observed were overweight and obesity including $44.9 \%$ of the participants, elevated blood pressure including $12.7 \%$ of participants, being a current smoker including $7.0 \%$ of participants, elevated blood glucose including 3.8\% of participants, and elevated lipid levels including $3.2 \%$ of participants. Males were found to have more risk factors than females.

Many participants reported some physical activity, with moderate levels being most frequently reported at $41.1 \%$. Low levels of physical activity were reported as $27.2 \%$, vigorous levels being at $25.9 \%$, and $7 \%$ reported as being sedentary. Diet was assessed by how often per week the individual ate outside of home, how frequently they ate red meat, if they drink sugary beverages. Of these responses, $50 \%$ of participants ate outside of home 2-3 times per week, 3 reported eating outside of home weekly, $81 \%$ reported consuming sugary beverages, $43.7 \%$ 
consumed red meat seldomly, and $36.7 \%$ consumed red meat 2-3 times per week. In terms of assessing the general knowledge of cardiovascular disease risk factors, the sample displayed a high knowledge level of cardiovascular disease risk factors with a mean score of 13.9 out of 16 points. In terms of assessing the perception of cardiovascular disease risk factors, the sample displayed a high level with a mean score of 20.8 out of 33 . Their results indicated that the occurrence of risk factors in this sample was like earlier reported research.

The researchers concluded that college students are a targeted population that could benefit from cardiovascular risk factor reduction programs. They mentioned that the lack of awareness and screening are of concern to researchers and it should be addressed. In general, there is enough literature to support the risk of cardiovascular disease in college students as they age, especially if preventive measures and/or intervention do not start early.

Lastly, Thiangalingam, U., Priya, V. V., and Gayathri R. conducted a brief study to expand on the knowledge of these modifiable risk factors, specifically. They wanted to assess attitudes, knowledge, and awareness of cardiovascular disease among college students. They obtained 100 college students. They gave them 10 questions which were a validated, online selfadministered questionnaire. This method was used to gather the data to each of them to avoid discussion among them and to avoid false results. Therefore, no bias is evidence in this study.

Their results showed that most of the students were aware of the cardiovascular risks present. To be exact, $85 \%$ of the students were aware of the risk factors present in cardiovascular diseases. Furthermore, $79 \%$ of students knew that physical inactivity affects cardiovascular disease, $95 \%$ were aware that obesity can cause cardiovascular disease, 93\% were aware that tobacco usage promotes cardiovascular disease, and 92\% were aware that a high cholesterol level 
and high blood pressure can cause cardiovascular disease. The researchers concluded that the epidemic of cardiovascular disease continues to grow, and it is due to the burden of cardiovascular risk factors. They stated that it is affecting younger generations and resources should be directed towards applying existing knowledge to tackle the disease epidemic. Moreover, they concluded that this survey got a positive result and they were able to spread awareness.

In conclusion, similar results were found across all the research. Majority of the research concluded that college age students are not aware about cardiovascular disease as they should be. Awareness and knowledge of the disease and its risk factors are low. In addition, most of the research pointed out how various behaviors of this population is putting them at risk. Such behaviors include physical inactivity, smoking, alcohol consumption, dietary habits, and stress levels. All researchers identified that heart disease can be prevented and starting at this age is most beneficial. College age students need more education at a younger age. It is important to reach universities to increase awareness. Health care providers can play a large role in this, and they should be educating on all aspects of prevention. Further research is needed to address and understand the level of awareness and various critical health indicators among this population. 


\section{References}

Alamari, H. (2019). Assessing healthy nutrition awareness among college students and the role of health education in promotion. College Student Journal, 53(3), 360-368.

Alshuwaiyer, G., \& Taylor, E. L. (2014). Awareness of heart disease among female college students. American Journal of Health Studies, 29(4), 287-301.

Appiah, D., \& Capistrant, B. D. (2017). Cardiovascular disease risk assessment in the United States and low- and middle-income countries using predicted heart/vascular age. Scientific Reports, 7, 16673(2017). doi:10.1038/s41598-017-16901-5

Arts, J, Fernandez, M. L., \& Lofgren, I. E. (2014). Coronary heart disease risk factors in college students, Advances in Nutrition, Volume 5, Issue 2, March 2014, Pages 177187, https://doi.org/10.3945/an.113.005447

Center for Disease Control and Prevention. (2019). Heart disease facts. Retrieved February 2, 2020, from https://www.cdc.gov/heartdisease/facts.htm

Mahan, K. L., \& Raymond, J. L. (2017). Food \& the nutrition care process $\left(14^{\text {th }}\right.$ ed.). St. Louis, MO: Elsevier.

McArdle, W., Katch, F., \& Katch, V.(2015). Essential of exercise physiology ( $8^{\text {th }}$ ed.). Wolters Kluwer.

McMahan, S. (2007). Cardiovascular disease risk perception and knowledge: A comparison of Hispanic and white college students in a Hispanic-serving institution. Journal of Hispanic Higher Education, 6(1), 5-18. https://doiorg.libproxy.lib.ilstu.edu/10.1177/1538192706294750 
Melnyk, J. A., Panza, G., Zaleski, A., \& Taylor, B. (2015). Awareness and knowledge of cardiovascular risk through blood pressure and cholesterol testing in college freshmen. American Journal of Health Education, 46(3), 138-143.

Nazar, M., Khan, A.S., Kumar, R. \& Hafeez, A. (2019). Effectiveness of health literacy intervention on cardiovascular diseases among university students of Pakistan. $B M C$ Health Services Research, 1, 1. https://doi-org.libproxy.lib.ilstu.edu/10.1186/s12913-0194348-y

Porth, C., \& Matfin, G., (2009). Pathophysiology: concepts of altered health states ( $8^{\text {th }}$ edition). Wolters Kluwer.

Ramey, S. L. (2005). Assessment of health perception, spirituality and prevalence of cardiovascular disease risk factors within a private college cohort. Pediatric Nursing, 31(3), 222-231.

Robinson, R., Roberson, K. B., Onsomu, E. O., Dearman, C., Nicholson, Y. M., Price, A. A., \& Winfield, V. D. (2019). Perceived risk of cardiovascular disease and health behaviors in black college students. Journal of Best Practices in Health Professions Diversity: Education, Research \& Policy, 12(1), 24-45.

Sarpong, D. F., Curry, I.Y. \& Williams, M. (2017). Assessment of knowledge of critical cardiovascular risk indicators among college students: Does stage of education matter? International Journal of Environmental Research and Public Health, 3, 250. https://doi-org.libproxy.lib.ilstu.edu/10.3390/ijerph14030250

Thiagalingam, U., Priya, V. V., \& Gayathri, R. (2019). Awareness on the risk factors of cardiovascular disease among college students. Drug Invention Today, 11(9), 2211-2213. 
Tran, D.-M. T., Zimmerman, L. M., Kupzyk, K. A., Shurmur, S. W., Pullen, C. H., \& Yates, B. C. (2017). Cardiovascular risk factors among college students: Knowledge, perception, and risk assessment. Journal of American College Health, 65(3), 158-167. https://doiorg.libproxy.lib.ilstu.edu/10.1080/07448481.2016.1266638 